\title{
The Views of Classroom Teachers on Project Tasks
}

\section{Davut KÖĞGE ${ }^{1} \bowtie$ Buket ASLANDAĞ $\breve{G}^{2}$}

'Niğde Ömer Halisdemir University, Faculty of Education, Department of Elementary Mathematics Education, Turkey

Email:kogced@gmail.com Tel:00903882254355

${ }^{2}$ Niğde Ömer Halisdemir University, Faculty of Education, Department of Curriculum \&̊ Instruction, Turkey

Email:buket.aslandag@gmail.com Tel:00903882254405

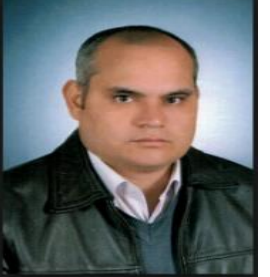

Corresponding Author)

\begin{abstract}
This study was conducted in order to determine the opinions of the class teachers regarding the project tasks. For this purpose, semi-structured interviews were conducted with 47 classroom teachers. The obtained data were subjected to content analysis using the MAXQDA 11 and "coding of the data" technique was used in the data analysis techniques. Consequently, it was concluded that the main purpose of classroom teachers in providing students with project skills is to develop research skills of students, to demonstrate creativity skills of the pupils, to make them use the knowledge and skills they have and enable them to produce an output. criteria that project tasks consider when evaluating are direct factors such as student activity and written exam success, and indirect factors such as adherence to the project schedule, and cleanliness, rigor and discipline of the project.
\end{abstract}

Keywords: Project tasks, Classroom teachers, Evaluation.

Citation | Davut KÖĞCE; Buket ASLANDAĞ (2018). The Views of Classroom Teachers on Project Tasks. Asian Journal of Education and Training, 4(3): 233-245.

History:

Received: 8 June 2018

Revised: 4 July 2018

Accepted: 9 July 2018

Published: 19 July 9018

Licensed: This work is licensed under a Creative Commons

Licensed: This work is
Attribution 3.0 License $($ (c)

Publisher:Asian Online Journal Publishing Group
Contribution/Acknowledgement: Both authors contributed to the conception and design of the study.

Funding: This study received no specific financial support.

Competing Interests: The authors declare that they have no conflict of interests.

Transparency: The authors confirm that the manuscript is an honest, accurate, and transparent account of the study was reported; that no vital features of the study have been omitted; and that any discrepancies from the study as planned have been explained.

Ethical: This study follows all ethical practices during writing

\section{Contents}

1. Introduction

2. Method

3. Findings

4. Discussion

References 


\section{Introduction}

From 2005-2006 education year, primary education ( $1^{\text {st }} 5^{\text {th }}$ class) curricula have been revised, and revised again in 2009 and 2015 and applied to all primary schools attached to the Ministry of National Education. Ministry of Education demonstrates the necessity of renewing the curricula; as the fact that our education system is not in harmony with the countries that are scientifically and economically developed, and that the success rate is in very low in the field of mathematics on the domestic (SBS, LGS) and international (TIMSS, PISA) tests (Olkun and Aydogdu, 2003; MEB-ERDD, 2005; Esen and Güneş, 2012; Pınar and Dinç, 2013). Although it is not explicitly stated in primary education mathematics curricula, it is understood that the constructivist approach is adopted (Akbayır et al., 2006). As a result of this approach, the teacher-centered traditional teaching approach has been abandoned and a student-centered teaching method has been adopted (Gelbal and Kelecioğlu, 2007). This change in the curricula has generated radical changes in the methods, techniques and understanding of the assessment and evaluation methods of the courses as well as the contents of the courses, teaching methods and the teaching materials and instruments used (Korkmaz and Captain, 2005; Gelbal and Kelecioğlu, 2007; Coklar et al., 2009). Criticisms have been introduced in multiple-choice exams in the United States since 1990 (Palm, 2008) because of the limitations of traditional assessment and evaluation methods in assessing students' learning during the teaching process (Sambell et al., 1997). Along with the renewed curricula, alternative assessment and evaluation approaches have gained importance for overcoming these limitations and critics (Gelbal and Kelecioğlu, 2007; Duban and Küçükyılmaz, 2008; Gömleksiz and Kan, 2010).

While traditional assessment and evaluation methods are based on product-based evaluation methods (Acar and Anil, 2009) alternative assessment and evaluation methods are based on process-based evaluation methods and techniques (Duban and Küçükyllmaz, 2008). In other words, when traditional assessment and evaluation approach tries to determine whether the students know or do not know a knowledge or whether they have a skill or not; in the alternative assessment and evaluation mentality, it is tried to determine the learning process of the students and to monitor the developments in the process (Acar and Anil, 2009; Şenel et al., 2009; Gömleksiz and Kan, 20 10).

Alternative assessment and evaluation approaches are theoretically based on constructivism (Anderson, 1998; Janisch et al., 2007). Thus, assessment and evaluation in constructivist learning take place at every stage of the learning-teaching process (Gelbal and Kelecioğlu, 2007; Karamustafaoğlu et al., 2012). Therefore, this approach which gives an opportunity to measure both product and process (Kuran and Kanatli, 2009) has increased the need for various measurement and evaluation tools (Baki and Birgin, 2002; Gelbal and Kelecioğlu, 2007; Karamustafaoğlu et al., 2012). Alternative assessment and evaluation include methods other than traditional paper and pencil tests and objective tests (Özenç, 2013). For example; in the 1998 primary school mathematics program, the use of traditional measuring instruments such as paper-pencil tests (written tests, oral tests, tests with correct answers and incorrect answers, short answers and matching questions, and multiple choice tests) was proposed (MEB, 1998). However, in addition to the assessment and evaluation tools used in the 1998 program in the new curriculum, the use of performance-based assessment tools (project, performance, product file, etc.) are also required (MEB, 2009a).

It is stated in the general objectives of the Primary School Mathematics Teaching Program that students are aimed to develop their skills in researching, producing and using information as well as problem-solving and reasoning skills (MEB, 2015). It is stated in many studies of literature that project tasks (assignments) play an important role in the development of these skills expected of the students themselves (Cakan, 2004; Gelbal and Kelecioğlu, 2007; Güvey, 2009). MEB (2009b) defines project tasks in the no. 2009/37 circular as "Projects are activities that help students identify and discover themselves, gain and develop scientific process skills, are selected from the lessons that are of interest to the students, and are selected from the courses they desire". It is stated in the Primary Mathematics Teaching (1-5th grade) curriculum that the students will do project work under the guidance of the course teacher (MEB, 2009a). If the teachers guide the students appropriately and make them carry out a project work; students' creativity, self-confidence at the start of a job, ability to distribute tasks in group work, leadership features and collaborative work, responsibility, open-mindedness and willingness to produce work can be obtained. This will be a crucial step in their preparation for their life as they will be able to examine real-life problems, find solutions, and actively participate in the learning process (Barak and Dori, 2005). It is also stated in the literature that project tasks or activities in the field are effective in increasing the success of students (Schneider, 2002; Ayaz and Söylemez, 2015). In project competitions and project duties, teachers are required to advise and guide their students in project preparation. This is because the teacher is the best person to get help in any question that students will encounter during project work. However, it is frequently stated in the literature that teachers have problems about project making and making students create a project (Baki and Tümer, 2009; Arı, 2010; Aydın and Çepni, 2011; Aydın et al., 2013; Özel and Akyol, 2014).

When the literature is examined, it is seen that studies related to project assignments are made within the scope of assessment and evaluation. In summary, it was revealed in these studies that projects were one of the top three most used by teachers in measuring student achievement (Gök and Sahin, 2009) that project assignments were used by most of the classroom teachers and that they controlled the students' project works (Özenç and Cakir, 2015 ) that $80.6 \%$ of the classroom teachers controlled the students' project works (Güneş, 2007) that classroom teachers gave notes in the grades of 1,2, and 3 according to criterions based on vague and teacher-based observations such as in-class performance and project grades (Arda, 2009) that classroom teachers gave project works because of official obligations (Güven and Eskitürk, 2007; Güneş, 2008) that the mathematics courses came first in the distribution of the project assignment numbers and that fourth and fifth grade students had the most difficulty in project works among their homework (Demirbaş, 2011). In addition, Yılmaz (2006) reported that classroom teachers had difficulties with their projects because the project assignments in the new primary school mathematics curriculum did not fit the students' level. However, Esen and Güneş (2012) conducted a study on the opinions of elementary mathematics teachers on project and performance tasks, although not with class teachers. It is seen that Esen and Güneş (2012) have carried out their work with a viewpoint as if project tasks and performance tasks are the same things. In other words, this study gives the reader the perception that the aim of 
the project task is the same as the purpose of the performance task. Looking at the purposes and outcomes of these studies, it is clear that none of them have investigated the thoughts of classroom teachers about project tasks and why they gave such tasks. If we want teachers to use project tasks in their lessons as an alternative teaching and evaluation tool, then what they understand from their project tasks and what kind of troubles they have experienced in their previous applications may provide important contributions to the program developers and researchers.

Although the project tasks have many positive effects on the cognitive, emotional and psychomotor development of the students, it is understood from the results of the above mentioned studies that there are many troubles in the implementation and evaluation of the project studies (Cakan, 2004; Gelbal and Kelecioğlu, 2007; Güvey, 2009). One of the possible causes of these difficulties may be the fact that classroom teachers have some incompleteness about the purpose of the project tasks, what they should pay attention to when project tasks are given, how project tasks should be assessed, and what to do in the process of making project tasks. It is important to identify the opinions of teachers who are in the guiding and router position in this process in order to overcome the difficulties experienced during the realization of project tasks used for alternative measurement and evaluation purposes. Therefore, this study was conducted in order to determine the opinions of the class teachers about the project tasks. Sub-problems that are sought in response to the main aim of the study are:

- What are the aims of classroom teachers to give project tasks in mathematics lessons?

- What are the points that classroom teachers pay attention to when determining project tasks in mathematics class?

- How do classroom teachers evaluate project tasks in mathematics class?

- What are the problems that classroom teachers encounter in the course of making students do project assignment in mathematics?

\section{Method}

\subsection{Research Design}

This study is a descriptive research carried out with the aim to find out the opinions of classroom teachers regarding project tasks. The study was performed using phenomenology among the qualitative research designs. Phenomenology design is used for the investigation of phenomena (events, experiences, concepts, perceptions, tendencies and situations) which one recognizes, but has no thorough understanding about. Interview is the basic data collection tool used in such type of researches (Yıldırım and Simşek, 2013).

\subsection{Study Group}

Within the framework of the purpose of research, the sample group was formed by 47 classrooms teachers working at the public schools in Niğde city center in Spring term of the 2014-2015 academic year, who participated in the research voluntarily.

\subsection{Data Collection Tool}

Research data were obtained through the semi-structured interview form according to the purpose of research. The main purpose of interview is to reveal out the emotions, opinions, and beliefs of the interviewed about the research subject through an interactive process (Cepni, 2009). In other words, the interview process helps the researcher to gain a deep understanding of the phenomenon investigated by the researcher (Büyüköztürk et al., 2012).

In this study, an interview form containing six semi-structured open-ended questions were used in order to reveal out the goals of class teachers and the issues they considered when assigning project tasks, evaluation of the projects tasks and the challenges they faced when having the students perform the projects tasks. Pre-specified questions are asked to the participant in a semi-structured interview. In addition, new questions may be asked where necessary or the interviewer may decide not to ask some of the questions (Yıldırım and Simşek, 2013). As open-ended questions enable the interviewed to explain his/her answers with their reasons, open-ended questions were used as the data collection tool (Gronlund and Linn, 1990).

The first question aims to reveal out the goals of teachers when assigning projects tasks; the second question aims to reveal out the factors considered by the teachers when assigning project tasks; the third and fourth questions aim to reveal out the evaluation process for projects tasks and the sixth and seventh questions aim to reveal out the challenges faced by the teachers when having the students perform the project tasks. This interview form was presented to two field education specialists in order to achieve content validity. The form was finalized by modifying the questions according to the opinions and recommendations of the specialists.

The questions used in the interview form are as follows:

- What is your purpose in assigning project tasks in Math class? Why do you assign project tasks to students in Math class?

- What are the issues that you consider when assigning project tasks in Math class? Which factors do you taking into account when assigning project tasks in Math class?

- How do you evaluate the project tasks you have assigned in Math class? Which criteria do you use in evaluation?

- Do the results of written exams or classroom performance have influence on you?

- Do you face challenges when having the students perform the projects tasks? If yes, what kind of challenges do you face?

- What are the challenges you face in terms of the students, parents, curriculum etc. when having the students perform the project tasks you have assigned? 


\subsection{Data Collection and Analysis}

Before starting the interview, each participating teacher was explained the purpose of the research and each interview question was asked one by one after the creation of a sincere communication environment. During the interview, some sub-questions were asked in addition to the basic questions in order to obtain more detailed information to make the participants clarify the issue some more. The interviews were recorded using digital voice recorder. The interview with each teacher took an approximately 45-50 minutes.

Each digitally recorded interview was turned into written document afterwards. When preparing the written documents, best efforts were given to import the interview records exactly. However, the lexical mistakes or deficiencies of the teachers interviewed were corrected, without affecting the sentence structure.

Data obtained were analyzed using the qualitative data analysis program called MAXQDA 11 and "content coding", among the data analysis methods, was used, as well (Yıldırım and Simşek, 2013).

In order to perform a reliable analysis of the data obtained, participants' responses to interview questions were analyzed by the researcher and an education specialist in an independent manner by making a classification based on the similarities and differences of these responses (Merriam, 1988; Yin, 1994). The level of coherence between the coding performed by the researcher and the field education specialist was calculated by the following formula: "Reliability $=($ Number of coherent categories)/(Total number of coherent and incoherent categories)" (Miles and Huberman, 1994). As a result of the calculation, the reliability degree of the coherence of the independent analyses carried out by the researcher and the field education specialist regarding the data on the purpose of assigning project tasks was found as $\alpha=.86$; regarding the data on the issues they took into account when assigning projects tasks, it was found as $\alpha=.85$; regarding the data on the evaluation of the project tasks, it was found as $\alpha=.88$; regarding the data on the challenges they faced when having the students perform the tasks, it was found as $\alpha=$.. Miles and Huberman (1994) conclude that; with regard to the coherence between two different encoders, a coherence score of 0.70 and above is sufficient for reliability. Accordingly, it was decided that the coherence between the encoders was reliable.

The codes and the sub-codes separately formed by the researcher and the field specialist were examined together. The similar ones were clarified and the non-similar ones were discussed (Merriam, 1988; Yin, 1994) and the consensus was reached on common codes and themes. These themes, sub-themes and codes created were used to produce figures with the MAXMaps feature of the MAXQDA qualitative data analysis program. These figures are presented in the findings section together with the frequency and percentage values of the codes and sub-codes (see Figure 1-6). When explaining the findings about the obtained data, a sample teacher response for each code is presented by making direct quotations. Each teacher is given a number ( $\mathrm{T}$ number) in the quotations.

Both the researcher and the field specialist conducting the data analysis have experience in qualitative research methodology. Both the researcher and field specialist have taken courses related to qualitative analysis, used qualitative data analysis method in doctoral dissertations and research articles. In this respect, it can easily be said that the encoders have experience in qualitative data analysis method.

\subsection{Validity and Reliability Measures}

In this study, the validity and reliability measures required for the qualitative research method are taken into account (Yıldırım and Simşek, 2013). For this purpose, in order to ensure internal validity, information was gathered during the implementation of the data collection tools by ensuring that participant teachers responded each question sincerely, thinking about their own practices regarding project tasks. In order to ensure external validity, the findings were tried to be presented in a manner consistent with the research questions.

In order to ensure external reliability, the data-analyst researcher's position in the research process, the conceptual framework used in data analysis, the codes and themes were defined; data collection and analysis methods were thoroughly clarified. In order to ensure internal reliability, the researcher and a field specialist took part in the analysis steps and the obtained data were presented through a descriptive approach.

\section{Findings}

The findings achieved in the analysis of the data which were obtained in accordance with the research purpose were interpreted with tables and descriptions given according to the research questions. Percentages may exceed $100 \%$ as the answers given by the participant teachers to each research question were placed under multiple codes.

\subsection{Findings on Purposes of Project Tasking}

The first research question was "What are classroom teachers' purposes of project tasking in the mathematics course?" The data obtained regarding this question are presented in Figure 1 and Figure 2. According to Figure 1, the classroom teachers' opinions on purposes of project tasking were grouped in three different themes of ensuring student development, alternative evaluation, and obligation by curriculum. Opinions on the theme of ensuring student development were grouped in four codes. Majority of the teachers stated that they task students with project to ensure students' cognitive, affective and psycho-motor development and improve their problem-solving skills.

As for the sub-codes in the cognitive code distinguished by percentage, $10.64 \%$ of the classroom teachers stated that they assign project tasks to improve students' thinking skills in the mathematics course. Despite being little in percentage, one each of the teachers stated that they task their students with projects to reinforce what students learned and improve their presentation skills while 2 of them reported that they do so to improve their knowledge on the subjects they learn about.

Also emphasizing some sub-codes (improving the research skill, exploring the creative skills, and improving independent working skills) of the problem-solving skills which is under the same theme, T20 reported that the purpose of project tasking is to improve students' mathematical thinking skills cognitively and provided the following statement: 
[T20]: Yes, I give project homework in the mathematics courses. I give project homework to improve students' skills of creativity, working independently, thinking and their mental skills. These are the most basic reasons. That is, the point is to enable students to do an original research. But most of the project homework does not achieve these goals...

Similarly to these statements, T13 provided the following statement to emphasize some of the sub-codes of both affective code (ensuring student's self-expression) and problem-solving skills (enabling students to learn by doing and experiencing and enabling them to their knowledge and skills):

[T13]: I give the project tasks to improve child's thinking, enable them to learn better by using their knowledge and skills, help them learn by doing and experiencing and express themselves among their friends, but their parents are doing all the projects. That is why we cannot achieve the desired objective...

As for the prominent sub-codes under the affective code in terms of percentage, $21.28 \%$ of the classroom teachers stated that they task students with projects to enable them to express themselves. On the other hand, 2 of the teachers stated that they give project tasks to improve students' cooperation with their peers and 3 of them reported that they do so to increase students' interest in and motivation of learning.

Also emphasizing some sub-codes (improving the research skill and enabling them to their knowledge and skills) of the problem-solving skills which is under the same theme, T9 reported that the purpose of project tasking is to students them to express themselves affectively and provided the following statement:

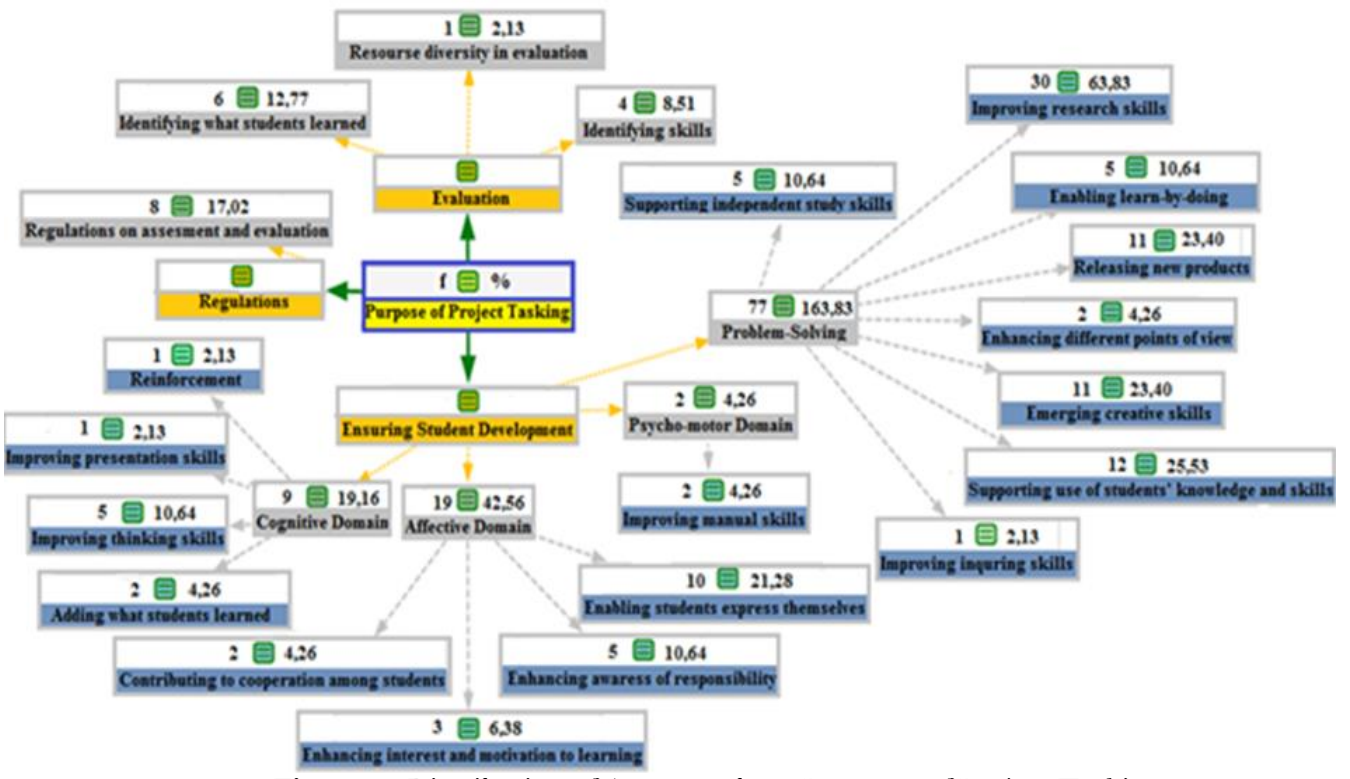

Figure-1. Distribution of Answers about Purposes of Project Tasking

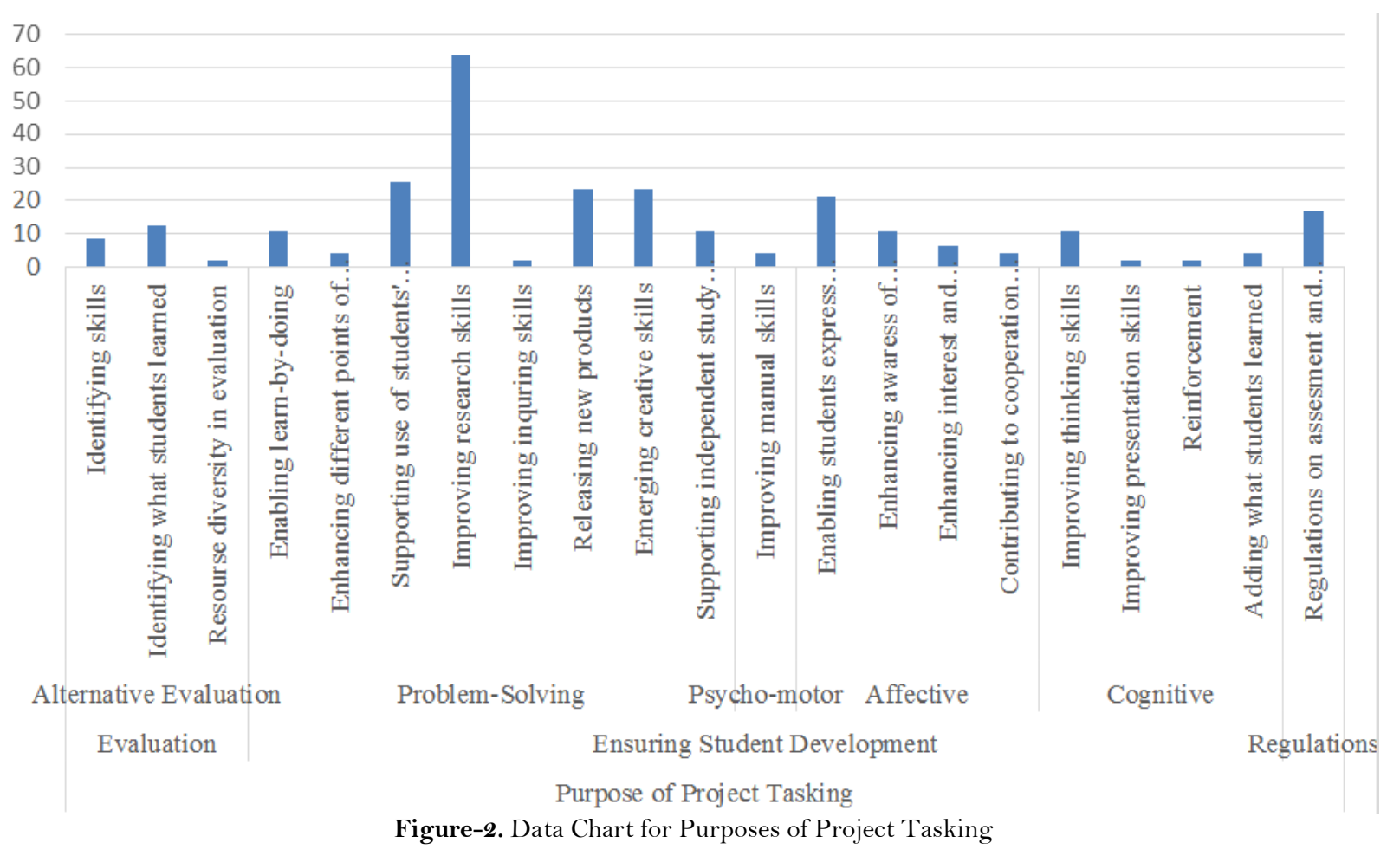

[T9]: Purposes of project studies include guiding children to research and improving their research skills, enabling them to establish good relations with people in their surroundings to utilize these relations, improving their esthetic feelings to enable them to express themselves and helping them use information they learned so that they can learn the subject in a better way.

Another sub-code under the affective code and emphasized by $10.64 \%$ of the participants is bringing the sense of responsibility to students. T5's statements on this sub-code and the codes of problem-solving skills (improving students' research skills) and alternative evaluation (ensuring source diversity in evaluation) are as follows.

T5: The point with project homework is to give responsibility to students and orientate them towards research. Indeed, one of the project purposes is that students gain the sense of responsibility. We give them homework to assign them with certain responsibilities. Certainly, there are those who do and do not gain. And evaluating the child in the classroom. We eventually give grades for school reports. Project homework is important for evaluating in an alternative way. 
Only 2 of the participants stated that they give project tasks in the mathematics course to help students develop psycho-motor skills. To provide an example, the following is the statements of T33 and 35 regarding this sub-code as well as both cognitive and problem-solving skill codes:

[T33]: The purpose of these tasks is to improve children's manual skills, open their horizon of thought and help them provide something from themselves, a new product.

[T35]: The point with the project homework is to help children put forth a concrete product by using their manual skills and what they have learned in the classroom as well as their social developments.

Regarding the sub-codes under the code of problem-solving skills, $63.83 \%$ of the participants stated that they task students with projects to improve their research skills. Furthermore, a significant part of the participants stated that they give project tasks to enable students to use their knowledge and skills (25.53\%), explore their creative skills $(23.40 \%)$, help them put forth a new product $(23.40 \%)$, improve their independent working skills $(10.64 \%)$ and enable them to learn by doing and experiencing $(10.64 \%)$. On the other hand, only one participant reported that he/she gives project tasks to improve students' mathematical questioning strength. The statements of T9, T13, T20 and T33 above can be seen regarding these sub-codes classified under the code of problem-solving skills. Moreover, emphasizing some of the sub-codes of problem-solving skills and the theme of obligation by regulation, T1 provided the following statements about the purpose of project tasking.

[T1]: The reason why I assign project homework is that we must do it by the regulation. Apart from that, it may enable

students to do research and produce new products and improve their questioning and thinking. I aim these when I give project tasks. But we cannot achieve the objective because homework is done superficially.

$17.02 \%$ of the participant teachers reported that the reason why they task students with projects is that they must do so because it is obligatory by regulation. Considering the above statement of T1 about these theme, it is seen that he/she is aware of the contribution to be made by project tasks to the students and must do it because it is obligatory by regulation. The following is the statement of T41 who reported that project tasks do not contribute to students at all and he/she give them because it is obligatory by regulation:

[T41]: This is an obligation; it is not a choice for teachers because it is required to evaluate student achievement by performances and projects in the elementary school regulation. I mean, it is mandatory. Therefore, we must give them. I would not do it. Because it is but an inconvenience for students. Students do not do it by themselves, anyway. They have their mothers or someone else do it.

It is understood from certain participant statements that project tasks are assigned to provide an alternative evaluation. Prominent statements under the alternative evaluation theme by percentage are finding out whether students have learned (12.77\%) and identifying students' abilities (4.51\%). T17's statement regarding these codes are as follows:

[T17]: The purpose of project homework is to see whether students learned and acquired the information. It is an evaluation to see the result of measuring certain manual skill or any other skill not for a week or two but in an extended period. I give projects so that students can do research and make examinations. I can see and evaluate whether students could learn and identify their abilities during the project process. The point is to evaluate the process and the product.

Furthermore, only T5 reported that he/she assign project tasks to ensure source diversity in evaluation. Regarding this code, you can see T5's statement above.

\subsection{Findings on Points Considered When Designating Project Tasks}

The second research question was 'What are the points considered by classroom teachers' when designating the project tasking in the mathematics course?" The data obtained regarding this question are presented in Figure 3 and Figure 4.

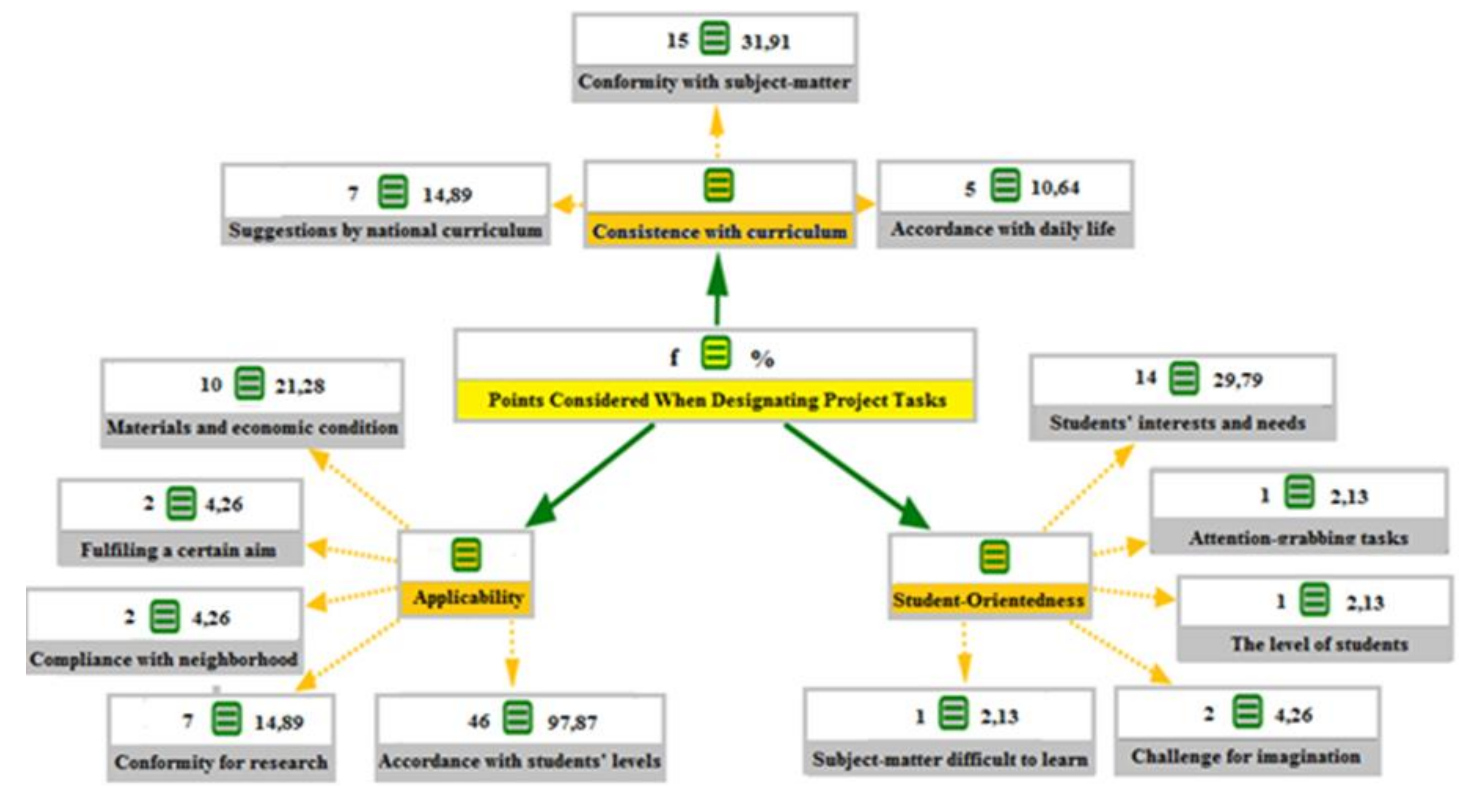

Figure-3. Findings on points considered when designating project tasks 


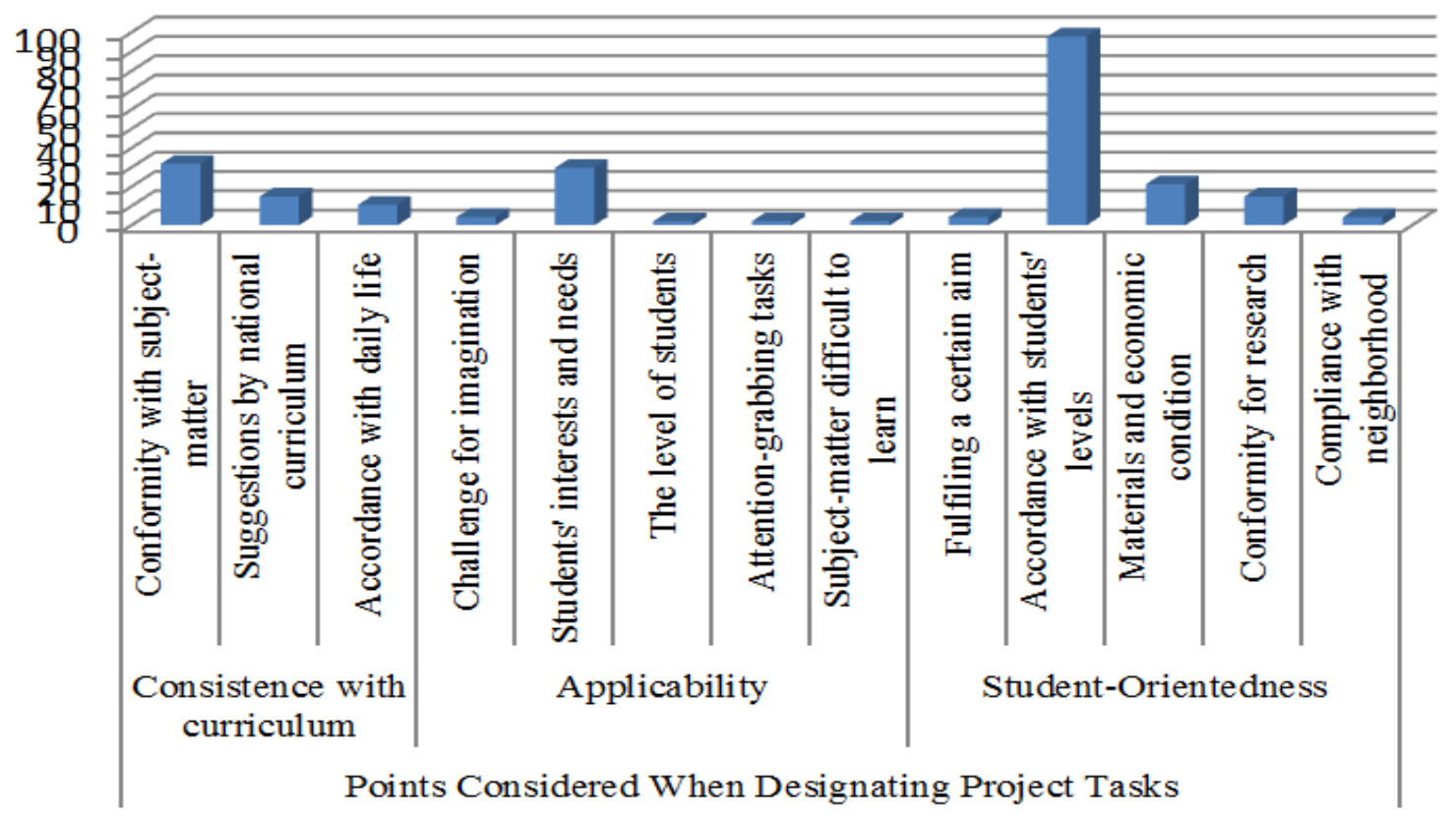

Figure-4. Data Chart for Points Considered When Designating Project Tasks

According to Figure 4, the classroom teachers' opinions on the points considered when designating project task gather in three themes of conformity with curriculum, student-orientedness and applicability.

As for the codes under the theme of conformity with curriculum, the participants reported that they assign project tasks by considering whether they are about the subjects of the course (31.91\%), whether they conform with MEB (Curriculum) recommendations (14.89\%), and whether they are associated with daily life (10.64\%). T32's statement regarding these codes are as follows:

[T32]: Since we assign children with project tasks to prepare them for life, I choose them from subjects which they can associate the daily life with. If they choose projects according to their own wishes and desires, they enjoy doing it and do research for it, which brings forth their researcher side... Therefore, I consider children's interests and wishes for sure. It also depends on course subjects. Even if they say they are particularly interested in a given subject, we cannot give a project on that subject if we are not instructing that subject during the year... I consider children's interests and wishes to the extent of the curriculum.

Another theme in regard to the points considered by the classroom teachers when designating project tasks is that they are student-oriented. It is observed that this theme includes five different codes. While $29.79 \%$ of the participant teacher consider students' interests and needs, 2 of the participants consider that projects challenge the imagination and one each of the participants considers students' levels and subjects which students have difficulty in learning, respectively, when designating the project tasks. T32's statement above and T43's statement below can be seen regarding the most emphasized code under this theme. Furthermore, T12 and T29 provided the following statements about these codes:

[T12]: It is generally up to students' wishes and interests. But we can sometimes designate it. And we sometimes assign

projects according to student levels as each student is on a different level. Since projects directly affect the grade, we task students who are poor in mathematics with projects so that they can have good grades...

[T29]: We have a curriculum to follow. Therefore, I pay attention to the fact that the subjects are intriguing also by considering the recommendations of the curriculum. I also consider that it is appropriate for children's levels. Because they do not tend to study all the time. It is expected from them at these ages. You cannot expect students to study constantly. That is why I am trying to find subjects that excite children's attention and intrigue them as much as I can.

I am careful about tasking them about a subject in which they have the biggest trouble.

Another theme in regard to the points considered by the classroom teachers when designating project tasks is that they are applicable. Opinions on the theme of applicability were grouped in five codes. Almost all of the teachers $(97.87 \%)$ reported they pay attention to the fact that the task is appropriate for students' levels, $21.28 \%$ of them consider instruments and economic opportunities, and $14.26 \%$ consider that project subject can be investigated by students when designating the project tasks. On the other hand, only two of the participants choose project subjects which will serve a certain purpose and other two of them designate project task in consideration of the environment in which students are living. Regarding the codes classified under this theme, T43 provided the following statement:

[T43]: Children's levels and ages are important when tasking them with projects. It matters if project homework can be investigated and done by them. I try to choose projects from which students can gain something, that is, which will contribute to them... And it is also important whether there is an environment in which children can do the project and do the research. The environment in which they are living is important... If they do not own computer and cannot afford instruments required for the project due to their economic opportunities, I give them a subject in consideration of that. I would not want my projects to impose economic burden on children.

\subsection{Findings on Factors Used for Evaluating Project Tasks}

The third research question was "How do classroom teachers evaluate the project tasks they give in the mathematics course?" The data obtained regarding this question are presented in Figure 5 and Figure 6. According to Figure 5, the data on the classroom teachers' opinions on how they evaluate the project tasks which they assigned students with in the mathematics course were grouped in two themes of indirect and direct factors. Opinions on the theme of direct factors were grouped in 11 different codes. 89.4\% of the participants reported that they use criterion (rubric) when evaluating the project tasks which they assign students with. Furthermore, 
significant part of the participant teachers stated that they evaluate the project tasks according to whether they comply with the project schedule (34\%), project task's cleanness, particularity and order (21.3\%), diversity of sources used when preparing the project task (14.9\%), and effort made during the process of preparing the (17\%). $10.6 \%$ of the participants reported that they evaluate projects according to how students present the projects and how they explain the information they acquired and $8.51 \%$ evaluate the projects by considering whether they put forth creative ideas. The following statements were provided by T26 and T39 about these codes:

[T26]: First of all, I use the criteria I designated when evaluating a project task prepared by students. ...did students prepare the project in a reasonable time or do it sloppily and hastily? ... did they add anything of themselves, use pictures or figures, and pay attention to it? Could they use their creativity or copy-paste it from the Internet? ... if they get a very high grade in the exam and actively participate in the class, I grant them a grade matching the exam. Child's state of mind at that moment is very important to me...

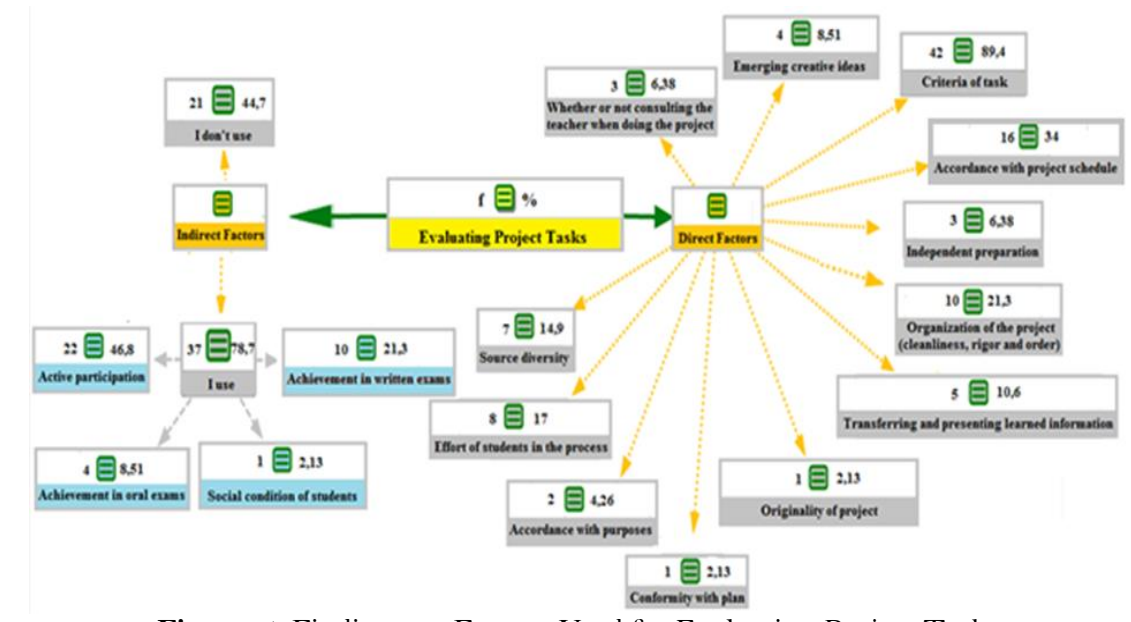

Figure-5. Findings on Factors Used for Evaluating Project Tasks

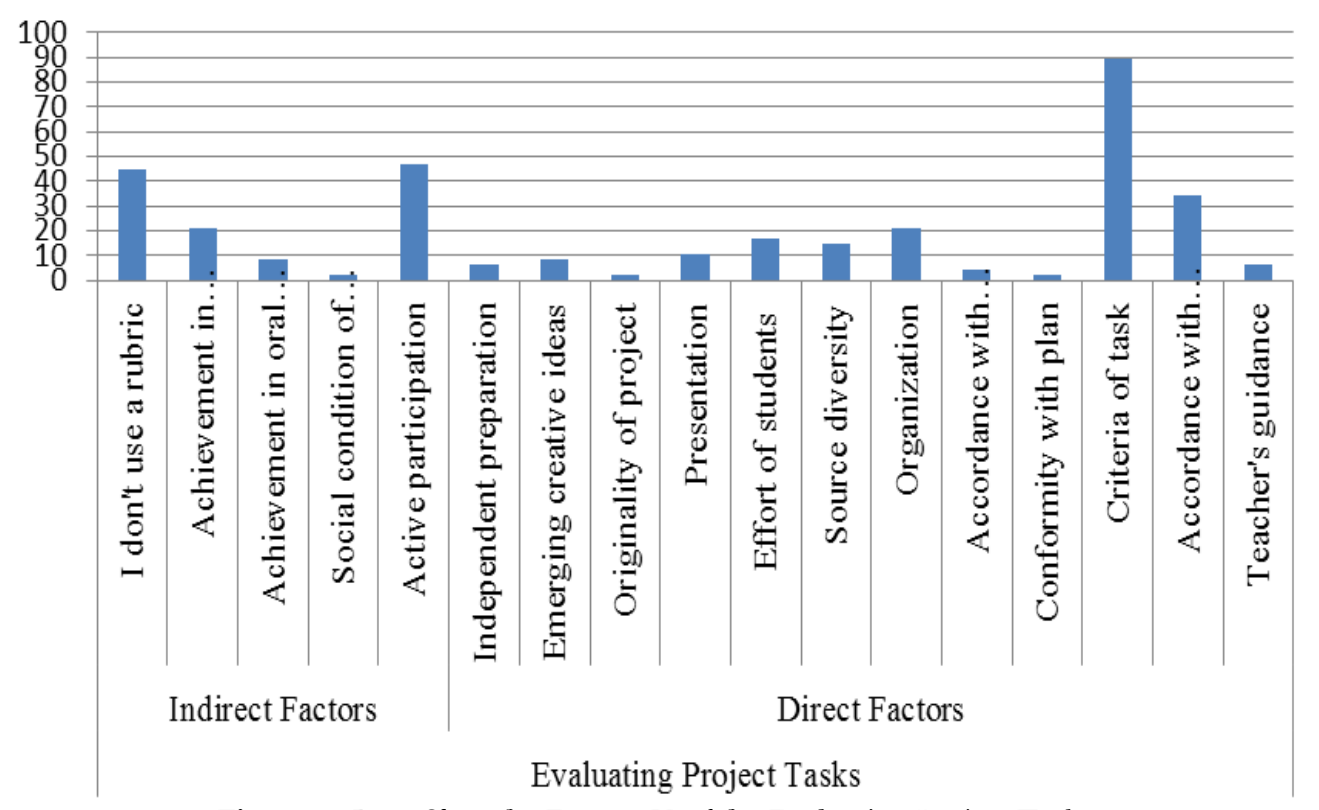

Figure-6. Data Chart for Factors Used for Evaluating Project Tasks

[T39]: We have evaluation forms that we prepared for these. We evaluate taking all the criteria in the evaluation form into account. Whether they made a good presentation, prepared the product nicely; the product is original, nice, clean, in an orderly fashion, attracted their friends' interest and attention... We take all these in consideration when evaluating... Apart from these, if they could not express themselves much in the project but they are good in the classroom and perform better, we grade the project as a supplement. Because we do not observe their studying just at that moment but within the year. We accordingly give grades.

On the other hand, despite being few in percentage, 3 each of the teachers evaluate projects considering whether students took teacher's guidance during the project and whether they did the project on their own respectively, 2 of them evaluate considering whether projects were prepared in accordance with the purpose, and 1 each of them evaluate considering whether they acted according to the plan and the originality of the information, respectively. Statements of T1 and T24 regarding these codes are as follows:

[T1]: ...We use standard criteria. But what matters to me time, planning... But if the research and tasks are not delivered within the planned time, doing it in a tight period of time does not serve to purpose... They should plan the time during which they do the project and collect the sources properly. Moreover, the studies during the process should be under guidance of teacher and teacher should show the student the path. And the student should inform the teacher of the preparation weekly... Students' participation in the classroom and their grades in written and oral exams certainly make us evaluate their projects positively... Their social status, family's status, and even the place we reserved for them in our emotional world necessarily intertwine. Eventually, you are a human; mischiefs of a successful child come to your attention less compared to other children. ...there are times when we make a high evaluation if a successful student has a trouble, thinking "he/she would have done it, but something must have gone wrong."

[T24]: I consider criteria like "Did students review the sources? Did they do the project by themselves? Was the project done according to the given purpose?" 
Opinions on the theme of indirect factors were grouped in two different codes of those who do and do not use indirect factors. $44.7 \%$ of the participant teachers stated that they do not consider any factor which is not related to the project task when evaluating students' projects. Statements of T6 and T23 regarding this code are as follows:

[T6]: There are various criteria for evaluating the projects. ...We evaluate what children prepare according to those criteria... Nothing is effective for me but those criteria. Even if one of them is the most hardworking student of the classroom, I would not give him/her high grade if he/she did not meet the criteria. I would consider whether he/she meet the criteria in that task.

[T23]: We have about 20 project evaluation criteria. We have evaluation criteria such as language, narration, bibliography, what students benefited from, what the original parts of the project are. We grade students by evaluating according to these criteria. I do not mix students' in-course achievement with the project grade.

Opinions of the teachers who stated that they use indirect factors when evaluating the project tasks were grouped under four codes. The participants stated that they consider students' activity in the course (46.8\%), achievement in written exams $(21.3 \%)$ and achievement in oral exams $(8.51 \%)$ when evaluating the project tasks. Only one of the participant teachers reported that social status of students' families is effective when evaluating the project tasks. The above statements of T1, T26 and T39 can be seen in regard to these subthemes.

\subsection{Findings on Problems Faced in Project Tasking}

The fourth research question was "What problems do classroom teachers face in project tasking in the mathematics course?" The data obtained regarding this question are presented in Figure 7 and Figure 8.

According to Figure 7, 3 subthemes that are curriculum, student-related and parental problems were achieved regarding the problems faced by the classroom teachers in project tasking in the mathematics course. Only one of the participant teachers reported to be having time trouble as the curriculum is intensive. The following is T8's statement:

[T8]: For example, a child whose manual skills is not improved or who have no conscious of the homework has his/her parents or others do the project. Evaluation must be done healthily, but we always look at the result. A completed project comes along, and we consider that the student has done it. It is obviously not the case. Even when a parent comes to me and asks, "What grade did my child take for this project", it is the evidence that the child did not do it... Children with a good financial status have the project done by others in a nice way, others take low grades because they cannot do it. It must be monitored, but we do not have the time. The curriculum already takes too much time. I cannot find time to speak personally even when a project requires.

Another problem faced by $21 \%$ of the participant teachers in project tasking is student-related. One of the participants reported that students cannot designate a project subject, 3 each of the participants reported that students cannot comprehend the purpose of project, students resort to copy paste the project from diverse sources, and they elude responsibility during the project, respectively.

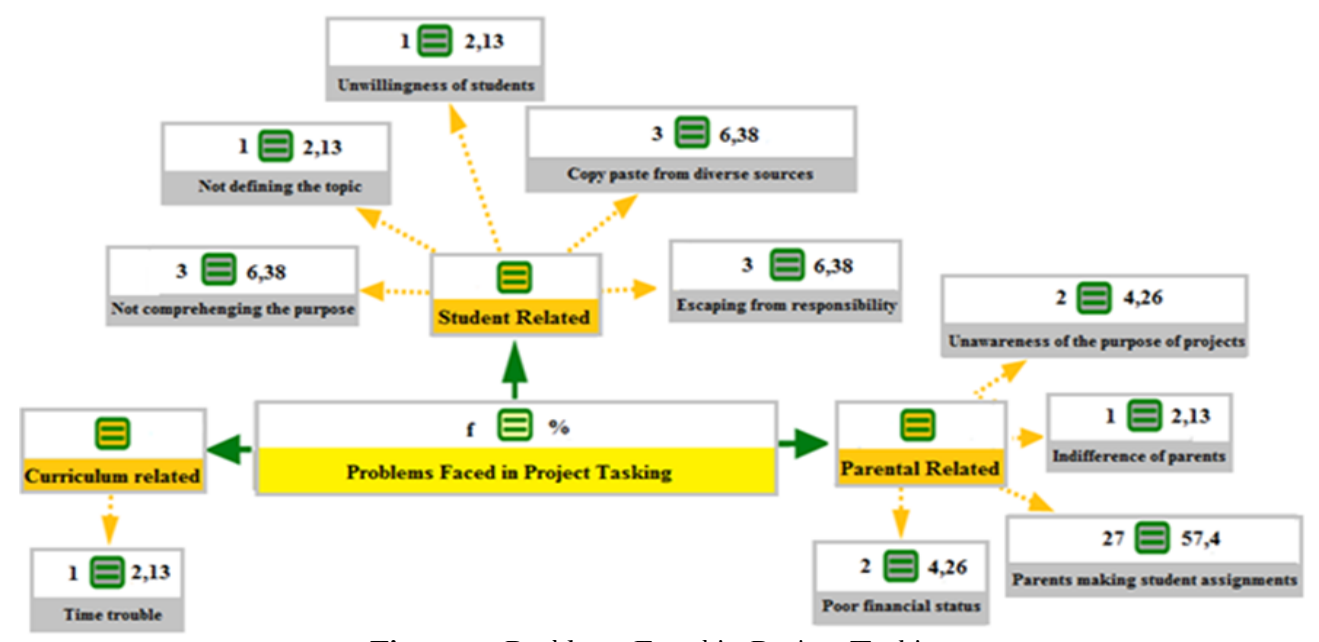

Figure-7. Problems Faced in Project Tasking

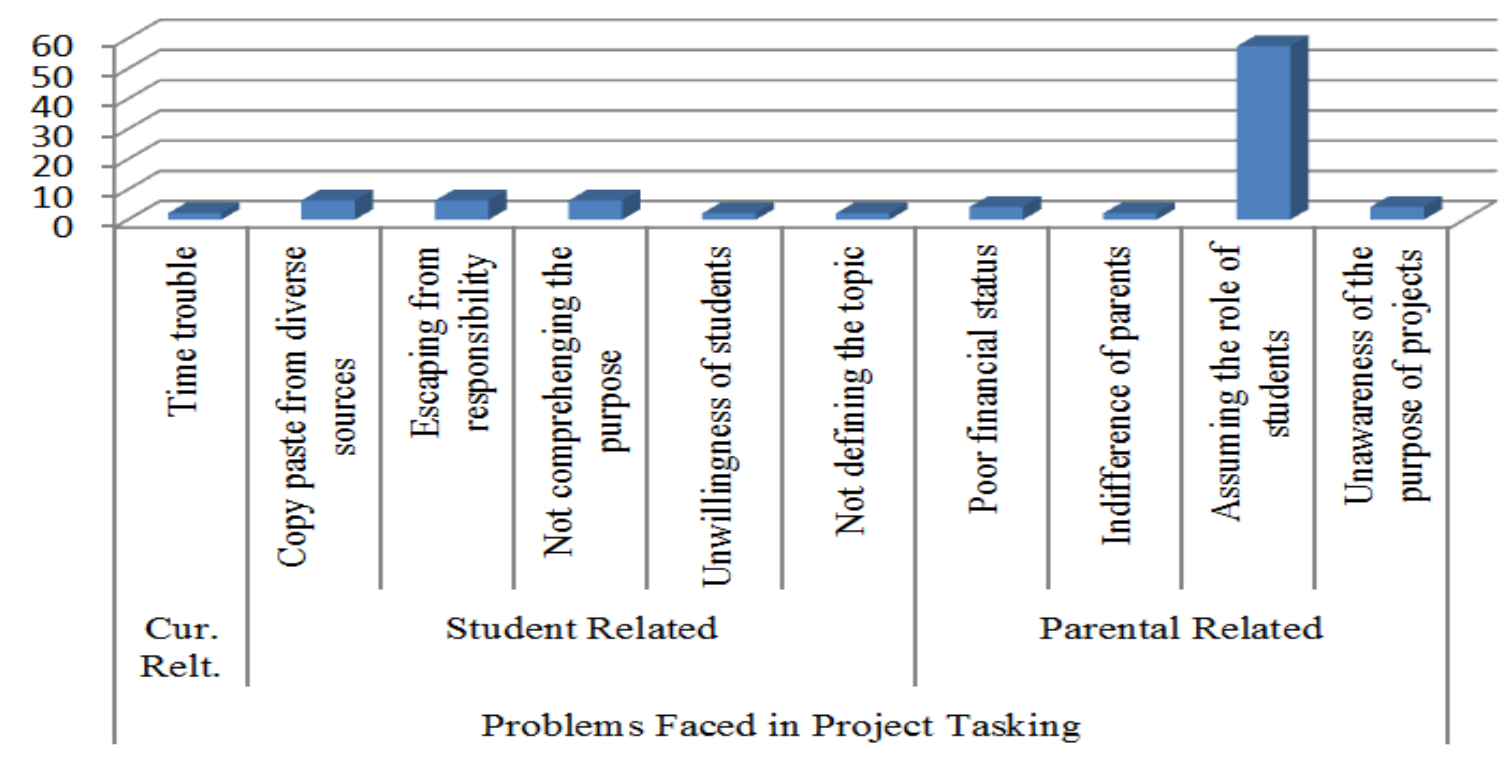

Figure-8. Data Chart for Problems Faced in Project Tasking 
T37's statement regarding these codes are as follows:

[T37]: Children do not want to put much effort forth and go online and print out whatever they find there. They should investigate, examine, exemplify and should not print out anything as it is. They never question whether what they find on Internet serves the purpose of the project. Next thing you know, the kid has not understood the purpose even on the last day of deadline. They have their parents or others do it in a hurry... We assign these tasks so that children can take their own responsibility. ... Some of the parents do the homework instead of the student as if we gave it to them. Children also say "My mother, father did it"...

$76.2 \%$ of the participant teachers reported that they have parental problems during the project tasking. Parental problems were grouped in four different codes. One of the participants mentioned about parents' indifference by stating that they do not contribute materially or spiritually to students whatsoever. Reporting that parents think that the project tasks for students are given to them, two of the participant teachers stated that parents are not aware of the reason why teachers assign the project tasks. Other two of the teachers stated that they encounter problems because parents with poor financial status cannot give financial support to their children for procuring the project materials. According to $57 \%$ of the participant teachers, the biggest problem they face in project tasking is parents who assumed the role of student and do their projects. The following is the statement of T1 who reported that he/she has parental problems in project tasking:

[T1]: We see many problems; first of all, we cannot explain our purpose to the parent completely. Some of the parents acts like we assign them with the project. Some of them do not even care. Therefore, we cannot achieve the results we hope. Another problem is that I want students to find their project subjects according to their interests; I have to designate the subjects because they are indifferent or do not know what to do. They sometimes choose a subject which they are interested in regardless of their parents, but it becomes a problem because the parents cannot provide financial support. Some of the parents do not mind at all, others do the project instead of students as if we assigned them with the projects. A competition starts among parents to get their own children higher marks. There are lots of flaws here, but I think the thing to do is to inform parents of the projects properly. If a project is not done by students but their parents, it is not fair for students whose parents care less or have poor financial level. And we have trouble when evaluating the projects and evaluating for the grade...

\section{Discussion}

In the study, the views of classroom teachers on project tasks in mathematics classes were examined. Looking at the findings of classroom teachers purpose of assigning project work in mathematics class, there are three main purposes.

One of the primary purposes of classroom teachers to assign project tasks is to provide mathematical student development. Classroom teachers give project assignments in mathematics classes to help students improve their cognitive, emotional and psychomotor development and to improve their problem-solving skills. While class teachers give project tasks to improve students' thinking ability in terms of cognitive domain, it has been found out that cognitive aspects of students are to improve their knowledge, to reinforce what they learn, to give presentation tasks and to improve presentation skills. Slater (1993) emphasized that it is important for teachers to conduct performance-based studies in terms of education and training process, thus ensuring that the project tasks given to the students can consolidate the course content. From the point of view of the effective field, they give project tasks in order to make students express themselves and to gain responsibility awareness. In addition, a small proportion of the teachers seem to have given project tasks in order to increase their interest and motivation to learn and to cooperate with peers of the effective students. Although the psychomotor is low in terms of area, class teachers also give the project task to improve the hand skills of students in mathematics class. Given the findings on improving problem-solving skills, it has emerged that two thirds of classroom teachers assign project tasks in order to improve students' research skills, close to a fourth of them use their knowledge and skills, to reveal creativity skills and create a new product. In addition, one-tenth of class teachers give project assignments in order to improve students' ability to work independently in mathematics lessons and to make them learn by doing. The results of the primary school teachers' task assignment purposes are generally matches by the objectives of the project tasks (MEB, 2014) specified in the Objectives of the Primary School Mathematics Class (1, 2, 3 and 4 Classes) Curriculum (MEB, 2015) and Preschool Education and Primary Education Institutions Regulation. Classes) Curriculum (MEB, 2015) and Preschool Education and Primary Education Institutions Regulation. The objectives of the project tasks in the Ministry of Education's Regulation on Preschool Education and Primary Education Institutions (MEB, 2014) defined as: "Project: Activities to be carried out in the guidance of the course teacher in order to examine, research and comment on a field or subject that the students want in groups or individually, to develop their opinions, to reach new information, to produce original ideas and inferences" Erdal (2007) stated that project tasks have directed students to explore and develop their self-esteem. Similarly, Esen and Güneş (2012) have shown in their work they made with elementary school mathematics teachers, half of the teachers participated assigning project tasks to improve students' research skills. Bozkurt et al. (2014) in their study on project and performance tasks with classroom teachers, it has been shown that every activity that students do themselves contributes to their development. In this regard, as a whole, the findings of the project tasks are summarized as follows: the primary objectives of the classroom teachers in project assignment to the students are, in order of significance: to develop students' research skills, to use their knowledge and skills, to introduce new products and to demonstrate creativity skills. Based on this result, it can be said that the class teachers are aware of the fact that their project tasks will contribute to the cognitive, emotional and psychomotor developments for the students and they give project tasks for this purpose.

One of the main objectives of classroom teachers to give project assignments in mathematics classes is to make alternative assessments. Approximately one in ten of the classroom teachers have emerged to give students project tasks to determine whether they have learned the topic and identify their talents.

One of the main reasons why primary school teachers give project assignments in mathematics lessons is that one of five teachers thinks that assignment of project tasks is mandatory due to regulations. As the fact that the teachers who have this view are not in a small ratio and the ratio of teachers who stated that the purpose of project 
task is to make alternative evaluation is also very low, it can be interpreted that classroom teachers do not fully understand the objectives of project tasks and do not consider project tasks as an alternative assessment tool. This result is in agreement with the results of the study conducted by Erdal (2007). Erdal (2007) showed that project tasks are one of the most used techniques that classroom teachers use for alternative assessment and evaluation, the reason for this is classroom teachers have enough knowledge about this technique. Similarly, Kuran and Kanatli (2009) found that one of the most used tools of classroom teachers as alternative assessment and evaluation techniques is project tasks. The reason for this is that the technique is well known by the teachers and that the program has indicated that it is compulsory. However, when we look at the findings of our study, it is clear that one of five teachers and one of five have indicated that they have given project tasks because it is compulsory due to regulations, it can be interpreted that a significant majority of the teachers, such as the four of five of them are not aware that project tasks can be used as an alternative evaluation tool. In addition, the fact that only one teacher has indicated that they give project tasks to students in order to provide a variety of resources in the measurement reminds that almost all of the teachers are aware that they do not have enough knowledge to make alternative evaluations. Esen and Güneş (2012) have supported the idea that only three teachers in the study they conducted gave project assignments in order to provide variety in measurement. Therefore, classroom teachers should be informed about the alternative measurement and evaluation methods and techniques through in-service training that will be organized both theoretically and practically.

When we look at the findings of the factors that class teachers take into consideration when designing project tasks in the mathematics classroom, it is seen that they take into account three different basic factors. One of these factors is that the tasks topics fit the curriculum. Approximately three-quarters of classroom teachers are concerned about the relevance of project topics and about one in ten pay attention to the proposals of mathematics teaching curricula and their relevance to everyday life. The low proportion of teachers who say that they pay attention to the relevance of project issues to everyday life means that a great majority of class teachers fail to provide project assignments that enable their students to relate mathematics to everyday life. The fact that teachers cannot give project topics in a way that will enable them to establish mathematics in relation to everyday life, that can cause students to look mathematics as mass of information that is to be memorized in and which is composed of formulas and symbols that are not related to daily life as a lesson. This will be one of the first obstacles to learning in a meaningful way for students to learn mathematics. This will be one of the first obstacles for students to learn by understanding mathematics in a meaningful way (Taşdemir, 2003). Therefore, classroom teachers should pay attention to the fact that they are related to daily life while determining the project tasks.

The second factor that class teachers take into account when setting project tasks is that project tasks are directed at students. Approximately one-third of the class teachers identify the project topics by taking the interests and needs of the students into account. However, very few teachers pay attention to the fact that the subjects are interesting and intriguing for students and that their imagination is compelling when they assign project tasks in mathematics. This result can be interpreted as almost whole of the classroom teachers, does not assign interesting and imaginative project tasks to students. Bozkurt et al. (2014) also determined that very low number of classroom teachers expressed the need for project and performance tasks to be given should be cognitively and imaginative for students. Based on this result, students will be able to do their homework more willingly and efficiently when the classroom teachers assign project tasks that will be able to draw on students' interests and make them wonder and use their imagination more effectively.

The third factor that class teachers take into account when determining project tasks is the ability to make project tasks. Almost all of the class teachers are concerned that the project tasks they are assigning to students are appropriate to the level of the students. This result can be interpreted as that the class teachers gave project tasks in accordance with the individual needs and levels of the students. In the study conducted by Esen and Güneş (2012) two thirds of the teachers showed that they gave project tasks by considering the levels of the students. Arranging the project tasks to be appropriate to the level of the students will increase the students' attitude towards the goal, and they will prepare and deliver the assignments willingly (Bozkurt et al., 2014). Also, two of five of the class teachers consider that the project tasks can be done in terms of equipment and economic facilities, and more than one in ten teachers consider the project to be explorable. Conversely, this shows that most of the teachers, almost three of five, have given project tasks without taking the students' equipment and economic opportunities and the discoverability of project fact into consideration. In addition, a small proportion of the teachers stated that while choosing project tasks, they selected the project to serve the purpose and that the environment of the student lives in also took into account. That is to say, although the class teachers indicate that they consider student levels while assigning project tasks, it is seen that the students equipment and economic opportunities and the environment they live in ignored. According to MEB (2009a) it is stated that the projects will improve the mental skills of the students such as creativity, research, communication, problem solving, and connection, if the project subjects given are appropriate to the level of the students and can be done according to local possibilities. Therefore, class teachers should choose the tools and materials that will be used in project construction that students can provide them with the local facilities, as well as taking into account the student's level when designing project tasks.

When we look at the findings of how class teachers evaluate project tasks in mathematics lessons, it is seen that they take two different basic factors, direct and indirect into account. While half of the classroom teachers do not take into account any factors other than the criteria in the project evaluation form that they have already identified when evaluating project tasks, the other half also use factors other than these criteria. As a ratio, half of the teachers take classroom activities of the students into account, two in five of them take written test results of the students into consideration during project task evaluation. This result is similar to the results of the work done by Esen and Güneş (2012). Esen and Güneş (2012) found that approximately four-thirds of elementary school mathematics teachers have shown that they consider students written examination successes in assessing their project tasks. They have stated that they have made an assessment taking into consideration factors such as student's classroom activity, written and oral examination successes which are not directly related to the process of preparation of the project and the product means that they cannot make a valid and reliable assessment. 
Therefore, when the activities of a student are measured and evaluated within the teaching process, the student's grades or scores from each tool must be assessed independently and objectively and the student's achievement status should be determined.

Based on the findings from the opinions about direct factors, it is seen that they made an evaluation considering some factors for the project task itself or for the construction process. Nearly nine-tenths of class teachers use criteria (rubrics) when evaluating student projects. Approximately one-third of the teachers using Rubrik seem to be more concerned about the fact that the student does not prepare and prepare the project in accordance with the project calendar, while it is seen that one of five of them consider the factors such as diligence, orderliness, cleanliness in the preparing of the homework and the diversity of the resources used in the homework preparing. In addition to these factors, they also use factors such as students ability to put forth creative ideas, take the guidance of the teacher in the project preparation process, ability to make project themselves, obey the purpose of the project, to make presentations and present the information they learn and behave in accordance with the plans they prepare. In the study conducted by Esen and Güneş (2012) a similar result was obtained when the mathematics teachers evaluated the student projects in terms of time, order and visuality, content, reasonableness, and presentation. Although an important proportion of teachers use criteria for project evaluation, the fact that teachers have significant differences in the usage rates of each criterion means that they cannot effectively use the criteria (rubrics) to evaluate projects. So, this result shows that class teachers cannot effectively assess the performance and achievement of students in the process from initial to finalization of the project. It is important that the classroom teachers are informed about the evaluation of the project (rubric) during the project evaluation since the project tasks should be assessed and evaluated effectively (Ersoy et al., 2010).

When we look at the findings related to the difficulties encountered by the class teachers in the process of making the project tasks given in the mathematics lessons to the students, it is seen that they meet three basic problems: students, parents, and curriculum. When considering student-related problems, very few prospective teachers face the following problems such as the students' failure to take responsibility, the direct copying of the project from different sources, the failure to understand the project purpose, determination of the project and the reluctance in project making process. In addition, there is only one teacher stating that there is a time constraint due to the curriculum intensity in project construction process. Conversely, the fact that fewer classroom teachers are faced with student and curriculum-related problems means that classroom teachers are not experiencing a lot of student-related problems during the project making process. Similarly; as a very small proportion of teachers have stated that they are facing parent-oriented problems such as economic support, the lack of interest of the parents, and the lack of awareness of the project purpose, can be interpreted in general that parents are interested in project assignments of their children and provide economic support. In contrast, according to more than half of the teachers, the most important problem they have experienced with parents is that they take a role of a student in the project making process and make the project instead of a student. Bozkurt et al. (2014) found that the most common problem for classroom teachers regarding project and performance assignments was the work done by the parents. This situation is an important problem that must be emphasized in terms of education e purpose of the project tasks given to the pupils, idea that their children cannot make a good homework, and wish for a high grade. Parents should be informed by the teachers at the beginning of the school year about how the parents can help their children in the homework making process, as homework made by parents may be a rescuer for the moment's success for students (Coşkun et al., 2009) but it can affect future achievements negatively. In terms of education, children supported by their parents have higher school achievement (Celenk, 2003). Furthermore, Ersoy et al. (2010) state that parents should help their children to take their own responsibilities instead of doing their homework so that they can get over the difficulties they may encounter in the future. Therefore, instead of doing the homework instead of the children, the parents should provide them with the materials needed for the homework and show a guiding attitude in the points where they are stuck or have difficulties to do their homework.

\section{References}

Acar, M. and D. Anil, 2009. The proficiency of classroom teachers to use the evaluation methods in the performance evaluation process, the problems they encountered and the solution proposal. TUBAV Science Magazine, 2(3): 354-363.

Akbayır, S., A. Baki, C. Öztürk, S. Çepni, N. Baysal and K. Kasım, 2006. New primary education programs (grades 1-5) with additional explanations for teachers and learners. Ankara: Pegem Academic Publishing.

Anderson, R., 1998. Why talk about different ways to grade? The shift from traditional assessment to alternative assessment. New Directions for Teaching and Learning, 1998(74): 5-16. View at Google Scholar $\mid$ View at Publisher

Arda, D., 2009. Examination of the qualifications and opinions of primary school teachers in the field of measurement and evaluation in the axis of 2005 curriculum. Unpublished Master Thesis. Marmara University, Institute of Educational Sciences.

Arl, A., 2010. Problems in implementation of project and performance tasks according to teachers. Journal of Electronic Social Sciences, 9(34): 32-55.

Ayaz, M.F. and M. Söylemez, 2015. Impact on the academic success of students of science project-based learning approach in Turkey: A meta-analysis study. Education and Science, 40(178): 255-283. View at Google Scholar

Aydın, M., A. Bacanak and S. Çepni, 2013. Investigation of needs of science and technology teachers about project-based instructional methods (PTÖY). Necatibey Education Faculty Electronic Science and Mathematics Education Journal, 7(1): 1-31.

Aydın, M. and S. Çepni, 2011. Investigation of the needs of teachers for the support of a project-based teaching method developed for science and technology teachers (PTÖY). Turkish Science Education Magazine, 8(1): 55-68.

Baki, A. and O. Birgin, 2002. Application of individual development file as an alternative evaluation in mathematics education, V. National Science and Mathematics Education Congress, Ankara.

Baki, A. and S.Ö. Tümer, 2009. Reflections from the project implementation process in an elementary school in the countryside. Elementary Online, 8(1): 146-158.

Barak, M. and Y.J. Dori, 2005. Enhancing undergraduate students' chemistry understanding through project? Based learning in an IT environment. Science Education, 89(1): 117-139. View at Google Scholar $\mid$ View at Publisher

Bozkurt, S., E. Aslanargun, S. Akın and A. Kilic, 2014. Opinions of primary school teachers about project and performance assignments. Pamukkale University Journal of Social Sciences Institute, 18(1): 157-173. View at Google Scholar

Büyüköztürk, S.., C.E. Kılıç, Ö.E. Akgün, S.Ş. Black and D.F. Amp, 2012. Scientific research methods. Ankara: Pegema Publishing.

Cakan, M., 2004. Teachers' measurement and evaluation practices and proficiency levels: Primary and secondary education. Ankara University Journal of Educational Sciences, 37(1): 99-114.

Celenk, S., 2003. On the school achievement: School family solidarity. Primary Education Online, 2(2): 28-34. 
Cepni, S., 2009. Introduction to research and project studies. 5th Edn., Trabzon: Üçyol Kitabevi.

Coklar, N., L. Vural and L. Sahin, 2009. Measurement and evaluation approaches that teacher candidates can use and self-efficacy of technology for measurement and evaluation. Journal of Social Sciences Institute of Adiyaman University, 2(3): 35-54.

Coşkun, E., İ. Gelen and M.O. Kan, 2009. Assessment of teacher and student opinions on performance assignments in Turkish lessons. Mustafa Kemal University Journal of Social Sciences, 6(11): 22-55. View at Google Scholar

Demirbaş, A., 2011. Assessment of homework applications in primary schools (Grades 1-5), Presidency of research and development. Ankara: Department of Ministry of National Education.

Duban, N. and E.A. Küçükyılmaz, 2008. Opinions of classroom teacher candidates regarding the use of alternative assessment methods and techniques in practice schools. Elementary Online, 7(3): 769-784.

Erdal, H., 2007. An evaluation of the measurement and evaluation part of the 2005 primary school mathematics program. Master Thesis, Afyon Kocatepe University Institute of Social Sciences, Afyonkarahisar.

Ersoy, A., B.Ö. Gürdoğan and E. Güvey, 2010. Project tasks in elementary education: The expectations of the class teachers from the velocity. Anadolu University Journal of Social Sciences, 10(3): 157-170.

Esen, O. and G. Güneş, 2012. Opinions of elementary mathematics teachers on project and performance tasks. Turkish Journal of Computer and Mathematics Education, 3(2): 115-130. View at Google Scholar

Gelbal, S. and H. Kelecioğlu, 2007. Teachers' perceptions of competence about the measurement and evaluation methods and the problems they faced. Hacettepe University Journal of Education, 33: 135-145. View at Google Scholar

Gök, B. and A.E. Sahin, 2009. The multiple use of assessment tools of primary and secondary school teachers and proficiency levels. Education and Science, 34(153): 127-143.

Gömleksiz, M.N. and A.Ü. Kan, 2010. An evaluation of the level of recognition of alternative assessment-evaluation approaches of the classroom teacher candidates. Eastern Anatolia Region Research, 9(1): 21-27.

Gronlund, N.E. and R.L. Linn, 1990. Measurement and evaluation in teaching. 6th Edn., New York: MacMillan.

Güneş, A., 2007. Classroom teachers' self-perception and assessment competencies. Unpublished Master Thesis. Marmara University, Institute of Educational Sciences.

Güneş, G., 2008. The reflection of the new elementary mathematics instruction program to the learning and teaching environment. Unpublished PhD Thesis, Karadeniz Technical University, Institute of Natural and Applied Sciences, Trabzon.

Güven, B. and M. Eskitürk, 2007. Methods and techniques used by cassroom teachers to measure and evaluate. XVI.Education Science Congress Paper, Detay Publications, Ankara, 3: 504-509.

Güvey, E., 2009. Teacher and parent opinions on project and performance tasks in primary education 1-5 grades. Unpublished Master Thesis, Osmangazi University Social Sciences Institute, Eskişehir.

Janisch, C., X. Liu and A. Akrofi, 2007. Implementing alternative assessment:Opportunities and obstacles. Educational Forum, 71(3): 221230. View at Google Scholar | View at Publisher

Karamustafaoğlu, S., A. Cağlak and B. Ogeci, 2012. Self-sufficiency of classroom teachers on alternative assessment tools. Amasya University Journal of Faculty of Education, 1(2): 167-179.

Korkmaz, H. and F. Captain, 2005. A review of the use of electronic portfolios to assess the development of students in science education. Online Journal of Educational Technology, 4(1): 101-106.

Kuran, K. and F. Kanatli, 2009. Assessment of opinions of class teachers on alternative assessment techniques. Mustafa Kemal University Journal of Social Sciences, 6(12): 209-234.

MEB-ERDD, 2005. PISA-2003 Project National Final Report (2005). Results of the OECD PISA-2003 Research Related to Turkey. Ankara: Ministry of National Education, Research and Development Department.

MEB, 1998. Elementary school mathematics curriculum: 1-8 classes. Istanbul: National Education Printing House.

MEB, 2009a. Primary mathematics lesson 1-5. Classes mathematics program. Ankara: Education Board of Education.

MEB, 2009b. Circular number 2009/37 on general directorate of primary education. Ankara: Project and Performance Duties.

MEB, 2014. Ministry of national education regulation on pre-school education and primary education institutions. Official Gazette, No: 29072.

MEB, 2015. Primary school mathematics course (1st, 2nd, 3rd and 4th grades) curriculum. Ankara: Education and Training Board Presidency.

Merriam, S.B., 1988. Case study research in education: A qualitative approach. San Francisco, C.A: Jossey-Bass.

Miles, M. and M. Huberman, 1994. An expanded source book qualitative data analysis. 2nd Edn., America: Pearson Education.

Olkun, S. and T. Aydogdu, 2003. What is the third international mathematics and science research (TIMSS)? Question what? Elementary Online, 2(1): 28-35

Özel, M. and C. Akyol, 2014. This is the problem and solution proposed in the preparation of my work projects. XI. National Science and Mathematics Education Congress, 11-14 September 2014, Cukurova University, Adana, Turkey.

Özenç, M., 2013. Determination of alternative assessment and assessment levels of classroom teachers. Dicle University Ziya Gökalp Education Faculty Journal, 21(1): 157-178. View at Google Scholar

Özenç, Ö. and M. Cakir, 2015. Determination of alternative assessment and assessment qualifications of primary school teacher s. Primary Education Online, 14(3): 914-933.

Palm, T., 2008. Performance assessment and authentic assessment: A conceptual analysis of theliterature. Proctical Assessment Research and Evalation, 13(4): 1-11. View at Google Scholar

Pınar, B.A. and A.P. Dinç, 2013. Assessment of primary mathematics teaching program. Journal of Research in Education and Teaching, 2(4): 164-171.

Sambell, K., L. McDowell and S. Brown, 1997. Study of student perceptions of the consequential validity of assessment. Studies in Educational Evaluation, 23(4): 349-371. View at Google Scholar

Schneider, R.M., 2002. Performance of students in project-based science classrooms on a national measure of science achievement. Journal of Research in Science Teaching, 39(5): 410-422.

Şenel, Ç.T., S.E. Nas and S. Cepni, 2009. The problems faced by science and technology teachers in using alternative assessment and evaluation techniques: Trabzon example. Journal of Yüzüncü Yll University Faculty of Education, 1: 122-141. View at Google Scholar

Slater, T., 1993. Classroom assessment techniques: Performance assessment. [Accessed 29.03.2016].

Taşdemir, M., 2003. Planning and evaluation in education, (program, teaching, management and evaluation). 2nd Edn., Ankara: January Publications.

Yıldırım, A. and H. Simşek, 2013. Qualitative research methods in the social sciences. 9th Edn., Ankara: Seçkin Publishing House.

Yılmaz, T., 2006. Teacher opinions about the renewed 5th mathematics program (Sakarya ili Örneği). Unpublished Master Thesis, Sakarya University Social Sciences Institute, Sakarya.

Yin, R.K., 1994. Case study research design and methods. 2nd Edn., Thousand Oaks, CA: Sage Publications. 